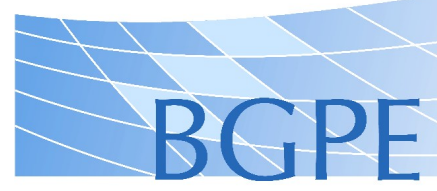

Bavarian Graduate Program in Economics

BGPE Discussion Paper

No. 186

\title{
Conditional cooperation: Type stability across games
}

\author{
Michael Eichenseer \\ Johannes Moser
}

June 2019

ISSN 1863-5733

Editor: Prof. Regina T. Riphahn, Ph.D.

Friedrich-Alexander-Universität Erlangen-Nürnberg

(c) Michael Eichenseer, Johannes Moser 


\title{
Conditional cooperation: Type stability across games*
}

\author{
Michael Eichenseer \\ University of Regensburg
}

\author{
Johannes Moser \\ University of Regensburg
}

June 11, 2019

\begin{abstract}
In this paper, we use an experimental setup to classify cooperation types using a sequential prisoner's dilemma and a one shot sequential public goods game. In these two games, we examine the within subject stability of cooperation preferences. Our results suggest that subjects classified as conditional cooperators in the prisoner's dilemma match others' contributions in the public goods game to a significantly larger degree compared to other types, which indicates a substantial consistency. Regarding discrete behavioral types, we find that the prisoner's dilemma performs well in identifying conditional cooperators while it is only an imperfect tool for identifying selfish types in the public goods game.
\end{abstract}

JEL-Classification: C72, C91, H41

Keywords: conditional cooperation, public goods game, sequential prisoner's dilemma, discrete behavioral types

*Eichenseer and Moser: University of Regensburg, Department of Economics, Universitätsstraße 31, 93040 Regensburg. Email: michael.eichenseer@ur.de; johannes.moser@ur.de. Michael Eichenseer and Johannes Moser acknowledge funding by the International Doctoral Program "Evidence-Based Economics" of the Elite Network of Bavaria. We would like to thank Wolfgang Buchholz, Francesco Fallucchi, Moritz Janas, Michael Kosfeld, Andreas Roider, and Christian Thöni for helpful comments. All errors remain our own. 


\section{Introduction}

One of the main contributions of behavioral economics is to establish the behavioral relevance of another type beyond the purely payoff-maximizing "homo oeconomicus", named "homo reciprocans", who represents a large fraction of the population. ${ }^{1}$ If a researcher needs to determine behavioral types of subjects in the lab, there are essentially two methods available to him. On the one hand, he can use the method introduced by Fischbacher, Gächter, and Fehr (2001) which relies on a conditional contribution vector elicited by the strategy method in a one-shot public goods game (FGF hereafter). ${ }^{2}$ This method is typically based on a set of 22 questions. ${ }^{3}$ On the other hand, a simple sequential prisoner's dilemma ( $S P D$ hereafter), for which only three questions are sufficient, can be used for type classification as well (Miettinen, Kosfeld, Fehr, and Weibull, 2017; Kosfeld, 2019; Eichenseer and Moser, 2019). For a researcher, the question arises whether using the simpler method is sufficient for type classification as it may save time and reduce cognitive load for the participants. To the best of our knowledge, there exists no systematic comparison of classification congruence between these two procedures.

Consequently, the aim of this paper is to assess the stability of classifications across games thereby contributing to the literature on the within subject stability of cooperation preferences (Blanco, Engelmann, and Normann, 2011; Volk, Thöni, and Ruigrok, 2012). To this end, we compare the types assigned by $S P D$ to those assigned by FGF in its latest refinements (Fallucchi, Luccasen, and Turocy, 2018; Thöni and Volk, 2018). The remainder of this paper will be as follows: Section 2 describes the experimental design and procedures. Section 3 presents and discusses our results. Section 4 provides as short summary and concludes.

\section{Design and procedures}

\subsection{Protocol}

The experiment was conducted on Amazon Mechanical Turk (MTurk henceforth) in December 2018 using a sample of MTurk experienced US residents. In total, 232 participants took part in the experiment earning $\$ 2.85$ on average with an average completion time of approximately 13 minutes. About half of the subjects

\footnotetext{
${ }^{1}$ See, for example, Fehr and Gächter (2000), Dohmen, Falk, Huffman, and Sunde (2009), and Kosfeld (2019).

${ }^{2}$ This method is by now the most commonly used one and, for example, labeled as 'PExperiment' in Fischbacher and Gächter (2010).

${ }^{3}$ As a second-mover, subjects are typically asked to specify their contribution conditional on the other players' average contribution for integers in the interval $[0,20]$. This results in 21 questions plus an unconditional contribution question for the role as first-mover.
} 
(120) played $S P D$ first, while the other half (112) was doing the $F G F$ task first. Subsequently, the participants completed a short questionnaire on age, gender, and education. Instructions for the experiment can be found in Appendix A.

\subsection{Sequential Prisoner's Dilemma (SPD)}

In the $S P D$ we have two players, indexed by $i=1,2$. Each player can choose between actions $S E N D(\mathrm{~S})$ and $K E E P(\mathrm{~K})$. Choices are elicited by using the strategy method such that Player 2 can condition his choice on the action of Player 1 . Figure 1 depicts the structure of the game in extensive form including the resulting final payoffs in POINTS (worth $\$ 0.05$ each). The social optimum is reached when Player 1 chooses $S$ and Player 2 responds with action $S$ as well. However, maximizing their own payoffs means that Player 2 will choose action $K$ at both decision nodes and Player 1 , who anticipates this behavior, chooses $K$ at the beginning. This is the unique subgame-perfect equilibrium of this game. Hence, the decision situation resembles a sequential prisoner's dilemma.

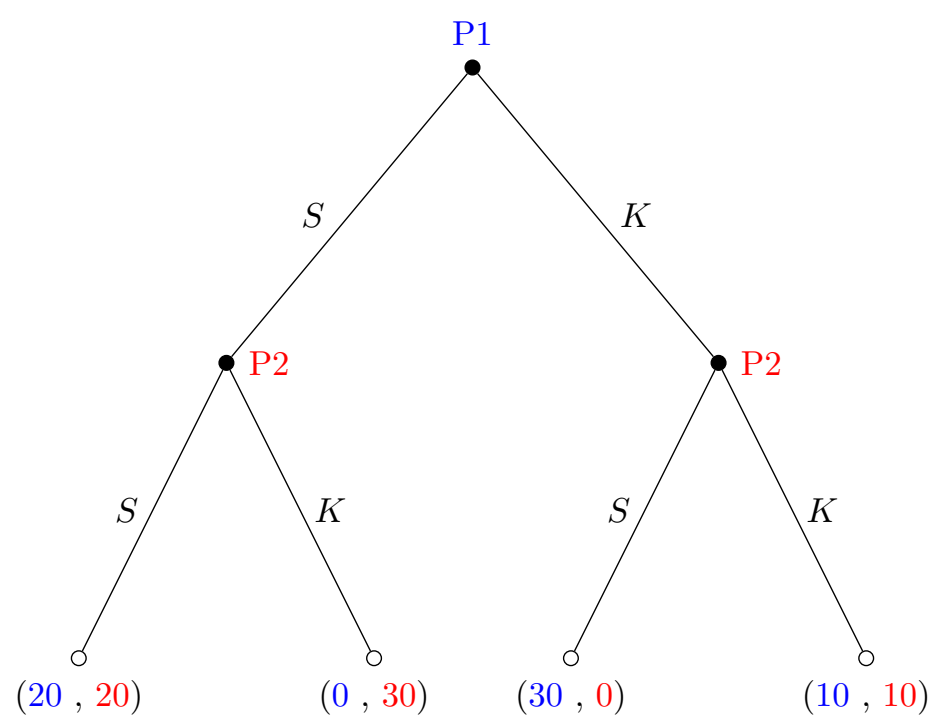

Figure 1: Payoff structure of the sequential prisoner's dilemma

All subjects state decisions for both being Player 1 and 2 (strategy method). They are randomly allocated to one of these roles at the end of the experiment and paid accordingly. The set of strategies, $X_{i}$, in this game for Player 2 is given by $X_{i}=$ $\{S S, K K, S K, K S\} .{ }^{4}$ Based on the participants' conditional second mover's choices, we can classify subjects as altruists (unconditional cooperators), conditional cooperators (cooperate only if the first-mover cooperates), free-riders (never cooperate), and mismatchers (counteract the other player) as depicted in Table 1.

\footnotetext{
${ }^{4}$ The first action is played when Player 1 chooses $S E N D$ and the second action is played when Player 1 chooses KEEP.
} 


\begin{tabular}{|c|c|}
\hline Cooperation type & Strategy \\
\hline \hline Conditional cooperator (CC) & $(S E N D, K E E P)$ \\
\hline Selfish (SF) & $(K E E P, K E E P)$ \\
\hline Altruist (AL) & $(S E N D, S E N D)$ \\
\hline Mismatcher (MM) & $(K E E P, S E N D)$ \\
\hline
\end{tabular}

Table 1: Cooperation types in $S P D$

\subsection{Sequential Public Goods Game (FGF)}

For the conditional contributions task in $F G F$, we used an adapted version of the procedure of Fischbacher, Gächter, and Fehr (2001). Four players, indexed by $i=1,2,3,4$, play a sequential public goods game in which one player makes his contribution after observing the other three players' rounded average contribution when they were moving simultaneously beforehand. The resulting payoff of player $i$ with initial endowment $y_{i}=20$ POINTS is given by:

$$
\pi_{i}=y_{i}-g_{i}+\alpha \sum_{j=1}^{4} g_{j}
$$

where $g_{i} \in[0,20]$ denotes individual contributions and $\alpha=0.4$ is the marginal per capita return (MPCR) of the public good. Choices are elicited by using the strategy method such that every player $i$ makes a choice both for being one of the three firstmovers (unconditional contribution) and being a second-mover (contribution table). As a second-mover, subjects condition their contribution $g_{i}$ on the average contribution (rounded to the next integer) of the first-movers which results in a conditional contribution path. Subjects are randomly assigned roles of first- and second-movers at the end of the experiment. For the type classification, only the contribution table of a subject is considered. The classification of Fischbacher, Gächter, and Fehr (2001) results in four types: a conditional cooperator whose contributions increase with other players' contributions, a selfish type who never cooperates, a triangle cooperator with hump-shaped contributions, and the remaining subjects who do not fit either one of the classifications.

Recently, there have been two proposals to refine the classification based on Fischbacher, Gächter, and Fehr (2001): (i) the method of Thöni and Volk (2018), which is based on the Pearson correlation coefficient and (ii) the method of Fallucchi, Luccasen, and Turocy (2018), which is based on hierarchical clustering. We will describe the behavioral types resulting from both refinements in Section 3.2. They have in common that they entail a behavioral type whose description comes close to the altruist in SPD: the unconditional cooperator (UC) in Thöni and Volk (2018) and the unconditional high type (UHC) in Fallucchi, Luccasen, and Turocy (2018). 


\section{Results}

\subsection{Contribution paths in $F G F$ by $S P D$ type}

As a first step in our data analysis, we provide a visual inspection to see whether there is a systematic relationship between behavioral types in $S P D$ and contribution paths in FGF which follow from which follow from the subjects' conditional contributions. Figure 2 depicts contribution paths in FGF by $S P D$ type. ${ }^{5}$

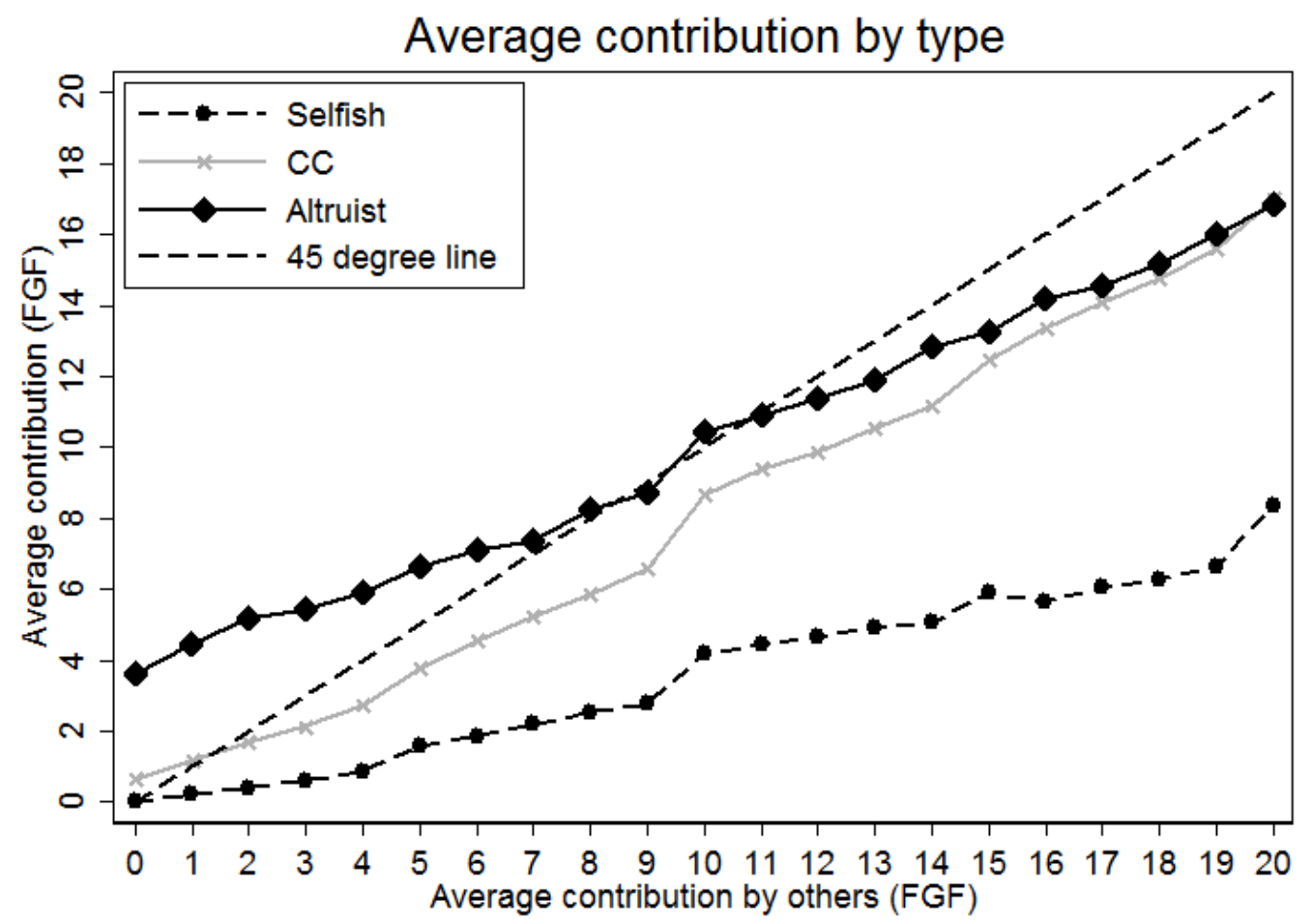

Figure 2: Contribution paths by $S P D$ classification in $F G F$

There are considerable differences between types. Compared to subjects classified as 'selfish' in $S P D$, contributions of 'conditional cooperators' (CC) have a decisively steeper slope in the contributions of others, i.e., they match others' contributions to a larger degree. In addition, subjects classified as 'altruist' in $S P D$ have the highest intercept which reflects that they give most when others give nothing. In line with expectations, 'selfish' types have, on average, the lowest conditional contributions for every level of average contributions of others.

In Table 2, we examine whether this visual interpretation can be supported statistically. Columns OLS(1) and Tobit(1) assume a common slope of all types in the average contribution of others (ACO) - and only different intercepts - whereas OLS(2) and Tobit(2) take different slopes for different SPD types into account.

\footnotetext{
${ }^{5}$ We excluded the mismatcher type in this graph, since it is a rare empirical phenomenon (9 of 232 subjects) whose behavior is difficult to interpret.
} 
The Tobit regressions consider observations censored at 0 and 20. Both regressions OLS(2) and Tobit(2) indicate that conditional cooperators show a significantly larger reaction to others' contributions compared to the reference category of selfish types. This corresponds to the graphical findings reported in Figure 2. Moreover, the coefficient of the intercept - the unconditional contribution - is largest for the altruist type and significantly different from the reference category of selfish types in the regressions OLS(1), Tobit(1), and Tobit(2).

\begin{tabular}{lcccc}
\hline & \multicolumn{4}{c}{ Contribution } \\
\cline { 2 - 5 } & OLS(1) & OLS $(2)$ & Tobit $(1)$ & Tobit $(2)$ \\
\hline Conditional cooperator & $4.573^{* * *}$ & 0.174 & $7.688^{* * *}$ & $3.394^{* * *}$ \\
& $(0.499)$ & $(0.350)$ & $(1.003)$ & $(1.021)$ \\
Altruist & $6.426^{* * *}$ & 3.781 & $10.299^{* * *}$ & $8.432^{* *}$ \\
& $(1.798)$ & $(2.410)$ & $(2.796)$ & $(3.639)$ \\
Mismatcher & $3.545^{* * *}$ & $2.339^{*}$ & $6.970^{* * *}$ & $7.415^{* * *}$ \\
& $(0.999)$ & $(1.278)$ & $(1.455)$ & $(2.142)$ \\
Avg. contr. of others (ACO) & $0.665^{* * *}$ & $0.394^{* * *}$ & $0.970^{* * *}$ & $0.720^{* * *}$ \\
& $(0.028)$ & $(0.045)$ & $(0.034)$ & $(0.061)$ \\
Conditional cooperator X ACO & & $0.440^{* * *}$ & & $0.387^{* * *}$ \\
& & $(0.055)$ & & $(0.074)$ \\
Altruist X ACO & & $0.265^{*}$ & & 0.148 \\
Mismatcher X ACO & & $(0.142)$ & & $(0.182)$ \\
& & 0.121 & & -0.075 \\
Constant & & $(0.144)$ & & $(0.188)$ \\
& $-3.071^{* * *}$ & $-0.358^{* *}$ & $-10.007^{* * *}$ & $-7.115^{* * *}$ \\
\hline Observations & $(0.359)$ & $(0.170)$ & $(1.017)$ & $(0.933)$ \\
Subjects & 4872 & 4872 & 4872 & 4872 \\
$R^{2}$ & 232 & 232 & 232 & 232 \\
Pseudo $R^{2}$ & 0.483 & 0.518 & & \\
\hline
\end{tabular}

Note: Cluster-robust standard errors (on the subject-level) are in parentheses. Tobit regressions account for 1,646 left-censored and 346 right-censored observations. ACO stands for "average contributions of others". The 'selfish' type serves as a reference category.

${ }^{*} p<0.1,{ }^{* *} p<0.05,{ }^{* * *} p<0.01$.

Table 2: Regression table - Contribution paths

\subsection{Relationship between classification methods}

We now investigate the relationship between the discrete behavioral types classified by SPD and FGF in the refinements of Thöni and Volk (2018) and Fallucchi, Luccasen, and Turocy (2018). The refinement of Thöni and Volk (2018) of FGF (FGF- $\boldsymbol{T}$ hereafter) resembles a theory-driven approach and is based on the Pearson correlation coefficient. It distinguishes the five behavioral types depicted in Table 3. 


\begin{tabular}{|c|c|}
\hline Type & Behavior \\
\hline \hline Free-rider (FR) & Zero contributions. \\
\hline Conditional cooperator (CC) & Monotonically increasing pattern in others' contributions. \\
\hline Unconditional cooperator (UC) & Constant contributions irrespective of what others do. \\
\hline Triangle cooperator (TC) & "Hump-shaped" contributions. \\
\hline Other & Undefined contribution pattern. \\
\hline
\end{tabular}

Table 3: Cooperation types in Thöni and Volk (2018)

In our sample, we can categorize 184 out of 232 subjects (79.3\%) as conditional cooperators (CC) using the $F G F-\boldsymbol{T}$ refinement. ${ }^{6}$ Conditional cooperators also constitute the largest group in $S P D$ with a share of $57.8 \%$. The second largest group are selfish types that account for $33.6 \%$ of all subjects in SPD and $13.8 \%$ in FGF-T. In both games, these two categories cover the vast majority of subjects. Table 4 reports the number and percentage of subjects falling into each possible combination of the two methods in a contingency table.

\begin{tabular}{|c|c|c|c|c|c|c|}
\hline \multicolumn{7}{|c|}{ Method FGF-T } \\
\hline & $F R$ & $C C$ & $U C$ & $T R$ & Other & Total \\
\hline Selfish & $\begin{array}{c}27 \\
(11.64 \%)\end{array}$ & $\begin{array}{c}44 \\
(18.97 \%)\end{array}$ & $\begin{array}{c}1 \\
(0.43 \%)\end{array}$ & $\begin{array}{c}5 \\
(2.16 \%)\end{array}$ & $\begin{array}{c}1 \\
(0.43 \%)\end{array}$ & $\begin{array}{c}78 \\
(33.62 \%)\end{array}$ \\
\hline$C C$ & $\begin{array}{c}4 \\
(1.72 \%)\end{array}$ & $\begin{array}{c}125 \\
(53.88 \%)\end{array}$ & $\begin{array}{c}2 \\
(0.86 \%)\end{array}$ & $\begin{array}{c}2 \\
(0.86 \%)\end{array}$ & $\begin{array}{c}1 \\
(0.43 \%)\end{array}$ & $\begin{array}{c}134 \\
(57.76 \%)\end{array}$ \\
\hline Altruist & $\begin{array}{c}1 \\
(0.43 \%)\end{array}$ & $\begin{array}{c}8 \\
(3.45 \%)\end{array}$ & $\begin{array}{c}2 \\
(0.86 \%)\end{array}$ & $\begin{array}{c}0 \\
(0.00 \%)\end{array}$ & $\begin{array}{c}0 \\
(0.00 \%)\end{array}$ & $\begin{array}{c}11 \\
(4.74 \%)\end{array}$ \\
\hline Mismatcher & $\begin{array}{c}0 \\
(0.00 \%) \\
\end{array}$ & $\begin{array}{c}7 \\
(3.02 \%) \\
\end{array}$ & $\begin{array}{c}2 \\
(0.86 \%) \\
\end{array}$ & $\begin{array}{c}0 \\
(0.00 \%) \\
\end{array}$ & $\begin{array}{c}0 \\
(0.00 \%) \\
\end{array}$ & $\begin{array}{c}9 \\
(3.88 \%) \\
\end{array}$ \\
\hline Total & $\begin{array}{c}32 \\
(13.79 \%)\end{array}$ & $\begin{array}{c}184 \\
(79.31 \%)\end{array}$ & $\begin{array}{c}7 \\
(3.02 \%)\end{array}$ & $\begin{array}{c}7 \\
(3.02 \%)\end{array}$ & $\begin{array}{c}2 \\
(0.86 \%)\end{array}$ & $\begin{array}{c}232 \\
(100.00 \%)\end{array}$ \\
\hline
\end{tabular}

Table 4: Types in SPD and FGF (Refinement of Thöni and Volk, 2018)

Comparing the classification of $S P D$ and $F G F-\boldsymbol{T}$, we see that slightly more than half of all subjects (125 of 232) are classified as CC according to both methods, while $11.6 \%$ are classified as selfish types in both games (27 of 232). Overall, only around $13.8 \%$ of the subjects (32 of 232) are classified in a category different from selfish or CC according to at least one of the methods. The results of a $\chi^{2}$-test suggests that the characteristics of both methods are not independent $(p<0.001)$. Hence, we can reject the null-hypothesis that there is no relationship between the two classification methods.

Conditional relative frequencies allow us to get a better picture of the type stability across games. About $93.3 \%$ of the subjects who are classified as CC in

\footnotetext{
${ }^{6}$ This is close to the $80.6 \%$ CC share reported in the US sample of Kocher, Cherry, Kroll, Netzer, and Sutter (2008).
} 
$S P D$, are also classified as CC according to $F G F-\boldsymbol{T}$. However, individuals classified as 'selfish' in $S P D$, are classified as 'selfish' according to $F G F-\boldsymbol{T}$ only in around $34.6 \%$ of the cases. This indicates that $S P D$ performs well in identifying subjects who have a consistent pattern of conditional cooperation across games, while this does not hold for selfish types.

Conversely, starting from $F G F$, subjects classified as CC according to $F G F-\boldsymbol{T}$, are in around $67.9 \%$ of the cases also CC in $S P D$, and those who are classified as 'selfish' according to FGF- $\boldsymbol{T}$ are in around $84.4 \%$ of the cases also 'selfish' in SPD. This means that $F G F$ is better suited to identify types who are classified as 'selfish' in both games compared to $S P D$.

\begin{tabular}{|c|c|}
\hline Type & Behavior \\
\hline \hline Own maximizers (OWN) & Zero contributions. \\
\hline Strong conditional cooperators (SCC) & Match others' contributions exactly. \\
\hline Weak conditional cooperators (WCC) & Increasing contributions, but less than one-for-one. \\
\hline Unconditional high contributors (UCH) & Contribute fully irrespective of what others do. \\
\hline Other & Undefined contribution pattern. \\
\hline
\end{tabular}

Table 5: Cooperation types in Fallucchi et al. (2018)

These findings are robust when changing to the refinement of Fallucchi, Luccasen, and Turocy (2018), which is based on hierarchical clustering and resembles a data-driven approach $(F G F-\boldsymbol{F}$ hereafter). The $F G F-\boldsymbol{F}$ categorization splits the $\mathrm{CC}$ category and distinguishes between weak conditional cooperators (WCC) and strong conditional cooperators (SCC). The type classification of $F G F-\boldsymbol{F}$ is depicted in Table 5. In our experimental sample, there has not been a distinct cluster of 'Other' types and, hence, we only consider four behavioral types.

\begin{tabular}{|c|c|c|c|c|c|}
\hline \multicolumn{6}{|c|}{ Method FGF $-F$} \\
\hline & $O W N$ & $W C C$ & $S C C$ & $U C H$ & Total \\
\hline & $\begin{array}{c}31 \\
(13.86 \%)\end{array}$ & $\begin{array}{c}37 \\
(15.95 \%)\end{array}$ & $\begin{array}{c}10 \\
(4.31 \%)\end{array}$ & $\begin{array}{c}0 \\
(0.00 \%)\end{array}$ & $\begin{array}{c}78 \\
(33.62 \%)\end{array}$ \\
\hline & $\begin{array}{c}11 \\
(4.74 \%)\end{array}$ & $\begin{array}{c}45 \\
(19.40 \%)\end{array}$ & $\begin{array}{c}74 \\
(31.90 \%)\end{array}$ & $\begin{array}{c}4 \\
(1.72 \%)\end{array}$ & $\begin{array}{c}134 \\
(57.76 \%)\end{array}$ \\
\hline Altruist & $\begin{array}{c}1 \\
(0.43 \%)\end{array}$ & $\begin{array}{c}2 \\
(0.86 \%)\end{array}$ & $\begin{array}{c}6 \\
(2.59 \%)\end{array}$ & $\begin{array}{c}2 \\
(0.86 \%)\end{array}$ & $\begin{array}{c}11 \\
(4.74 \%)\end{array}$ \\
\hline Mismatcher & $\begin{array}{c}0 \\
(0.00 \%)\end{array}$ & $\begin{array}{c}6 \\
(2.59 \%)\end{array}$ & $\begin{array}{c}3 \\
(1.29 \%)\end{array}$ & $\begin{array}{c}0 \\
(0.00 \%)\end{array}$ & $\begin{array}{c}9 \\
(3.88 \%)\end{array}$ \\
\hline Total & $\begin{array}{c}43 \\
(18.53 \%)\end{array}$ & $\begin{array}{c}90 \\
(38.79 \%)\end{array}$ & $\begin{array}{c}93 \\
(40.09 \%)\end{array}$ & $\begin{array}{c}6 \\
(2.59 \%)\end{array}$ & $\begin{array}{c}232 \\
(100.00 \%)\end{array}$ \\
\hline
\end{tabular}

Table 6: Types in SPD and FGF (Refinement of Fallucchi et al., 2018)

Table 6 presents the contingency table of types. Again, a $\chi^{2}$-test shows that the type classifications are not independent $(p<0.001)$, indicating a significant relationship between the two methods. If we look at the conditional relative frequencies, 
we see that conditional on being classified as CC type in $S P D$, the relative frequency is $88.8 \%$ to be classified as either WCC or SCC according to FGF-F. By contrast, a subject classified as selfish in $S P D$ is only selfish in $39.7 \%$ of the cases according to $F G F-\boldsymbol{F}$.

Starting from $F G F-\boldsymbol{F}$, a subject sorted in the group of selfish types according to $F G F-\boldsymbol{F}$, is also selfish in $S P D$ in $72.1 \%$ of the cases. By contrast, the relative frequency of being CC in SPD is only $65.0 \%$ when being classified as either WCC and SCC according to FGF-F. When distinguishing between WCC and SCC, we observe that in the group of those who are classified as WCC according to $F G F-\boldsymbol{F}$, only $50 \%$ are also classified as CC in $S P D$, whereas in the group of those who are classified as SCC, almost $80 \%$ are classified as CC in SPD. Thus, the distinction between WCC and SCC predicts the relative frequency of being $\mathrm{CC}$ in $S P D$ quite well. Likewise, the relative frequency of being selfish in $S P D$ is highest for OWN maximizers, followed by WCC and SCC types.

Figures 3 and 4 illustrate the respective intersections between $S P D$ and FGF for CC and selfish types - graphically by using Venn diagrams. The solid circles represent the respective sets of $\mathrm{CC}$ and selfish types according to $S P D$, while the dashed circles represent these types according to the FGF classification. The intersection of both circles illustrates the set of subjects who are of the same type according to both methods. In Figure 4 (left), the WCC and SCC types are pooled as conditional cooperators.
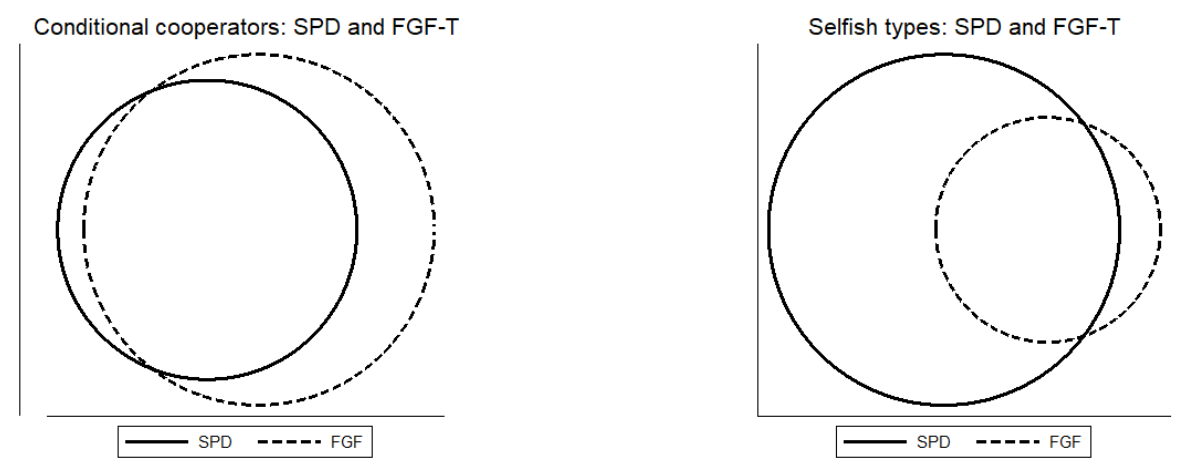

Figure 3: Venn diagrams of SPD and FGF-T (Refinement of Thöni and Volk, 2018)

The fact that the overlap between selfish types in $S P D$ and $F G F$ is quite small leaves room for further research. One hypothesis would be that the FGF method underestimates the share of selfish types. Confused types, who do not understand the rules of the game completely, may act as if they were cooperative types in $F G F$ (see Detemple, Kosfeld, and Kröll, 2019). Assuming that the SPD imposes fewer 
cognitive load on subjects would allow for the hypothesis that the share of confused types is lower in this game and, consequently, the share of selfish types should be higher in $S P D$ compared to the $F G F$ method. This might explain why many of the selfish types in $S P D$ behave cooperatively in $F G F$.
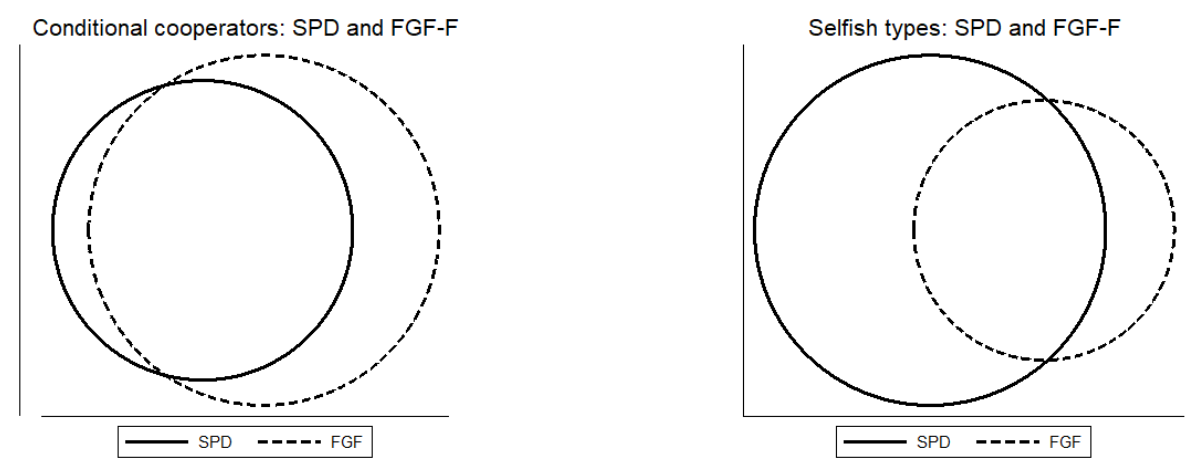

Figure 4: Venn diagrams of SPD and FGF-F (Refinement of Fallucchi et al., 2018)

\section{Summary and conclusion}

We provided an online experiment, in which we investigated the consistency of two methods for classifying different cooperation types. With regard to discrete behavioral types, our results indicate that $S P D$ performs very well in identifying subjects with a stable pattern of conditional cooperation. Given that a subject is of CC type in $S P D$, the probability is $93.3 \%$ to be classified as CC as well according to $F G F-\boldsymbol{T}$ (refinement of Thöni and Volk, 2018) and 88.8\% according to FGF-F (refinement of Fallucchi, Luccasen, and Turocy, 2018), respectively. We further observe that the distinction between WCC and SCC is helpful for identifying CC types in SPD more precisely, since the likelihood for being 'selfish' in $S P D$ is considerably higher for WCC types compared to SCC types.

Considering contribution paths in $F G F$, subjects classified as conditional cooperators in $S P D$ match others' contributions to a significantly larger degree compared to selfish types. This is captured in the significantly larger slope of their conditional cooperation path.

On this basis, we can conclude that if a researcher's objective is is to identify those subjects in a group who are, with a high probability, conditional cooperators in both games, the simple method of the $S P D$ is well suited for this task. If, on the other hand, the focus is on identifying selfish types, we cannot offer a clear conclusion. We observe many 'selfish' subjects in $S P D$ who show cooperative behavioral patterns 
in FGF. However, based on the hypothesis that there is a larger share of confused types in $F G F$, who act as if they were CC types, the simpler game $(S P D)$ is not necessarily a weak tool for identifying selfish types, but may be more accurate in measuring the true fraction of selfish types in the population (see Detemple, Kosfeld, and Kröll, 2019). 


\section{References}

Blanco, M., D. Engelmann, and H. T. Normann (2011). A within-subject analysis of other-regarding preferences. Games and Economic Behavior 72(2), 321-338.

Detemple, J., M. Kosfeld, and M. Kröll (2019). Confusion does not explain conditional cooperation in public-goods experiments. unpublished manuscript.

Dohmen, T., A. Falk, D. Huffman, and U. Sunde (2009). Homo reciprocans: Survey evidence on behavioural outcomes. The Economic Journal 119(536), 592-612.

Eichenseer, M. and J. Moser (2019). Leadership in dynamic public good provision: Endogenous growth and inequality. working paper.

Fallucchi, F., R. A. Luccasen, and T. L. Turocy (2018). Identifying discrete behavioural types: a re-analysis of public goods game contributions by hierarchical clustering. Journal of the Economic Science Association, 1-17.

Fehr, E. and S. Gächter (2000). Fairness and retaliation: The economics of reciprocity. Journal of Economic Perspectives 14(3), 159-181.

Fischbacher, U. and S. Gächter (2010). Social preferences, beliefs, and the dynamics of free riding in public goods experiments. American Economic Review 100(1), $541-556$.

Fischbacher, U., S. Gächter, and E. Fehr (2001). Are people conditionally cooperative? Evidence from a public goods experiment. Economics Letters 71(3), 397-404.

Kocher, M. G., T. Cherry, S. Kroll, R. J. Netzer, and M. Sutter (2008). Conditional cooperation on three continents. Economics letters 101 (3), 175-178.

Kosfeld, M. (2019). The role of leaders in inducing and maintaining cooperation: The CC strategy. The Leadership Quarterly, forthcoming.

Miettinen, T., M. Kosfeld, E. Fehr, and J. W. Weibull (2017). Revealed preferences in a sequential prisoners' dilemma: A horse-race between five utility functions. working paper.

Thöni, C. and S. Volk (2018). Conditional cooperation: Review and refinement. Economics Letters 171, 37-40.

Volk, S., C. Thöni, and W. Ruigrok (2012). Temporal stability and psychological foundations of cooperation preferences. Journal of Economic Behavior 8 Organization $81(2), 664-676$. 


\section{A Instructions}

\section{Basics}

This online experiment will consist of two parts.

First, part 1 will be explained. After part 1 ends, you will receive instructions for part 2. Your decisions in part 1 do not influence your payoff in part 2 and vice versa.

In this study you will earn POINTS. Each POINT is worth 0.05 Dollar (20 POINTS $=1$ DOLLAR). At the end of the study you receive your amount of POINTS cashed out in Dollar.

In this study, you must answer control questions to ensure that you have understood the task correctly (there are five control questions in total). Only if you answer them correctly you can complete this survey. The control questions require some small calculations. If you give a wrong answer to a control question, you can try multiple times until you find the correct solution.

\section{Treatment SPD}

You will be matched with one other random MTurker who also participates in this study. One of you has the role of "Player 1" and the other one has the role of "Player 2". Each of you is endowed with 10 POINTS. You have to decide whether you want to KEEP your 10 POINTS or whether you want to SEND your 10 POINTS. If the POINTS are sent, they double for the other player. The other MTurker has to make the same decision.

This game is played sequentially - i.e., the players make their decisions subsequently (this is illustrated by the graph below).

First Player 1 (BLUE) makes a decision. Player 2 (RED) observes this decision and makes a decision as well. In this study, you make a decision for both roles, Player 1 and Player 2 (follow for this purpose simply the instructions on the screens). At the end of the study, a random device determines the role of you and the other MTurker. There are two possibilities: you are Player 1 and the other MTurker is Player 2 or you are Player 2 and the other MTurker is Player 1. The combination of the decisions of you and the other MTurker determines your payoff in this game, as shown in the graph below.

Conversion rate: 20 POINTS $=1$ DOLLAR. 


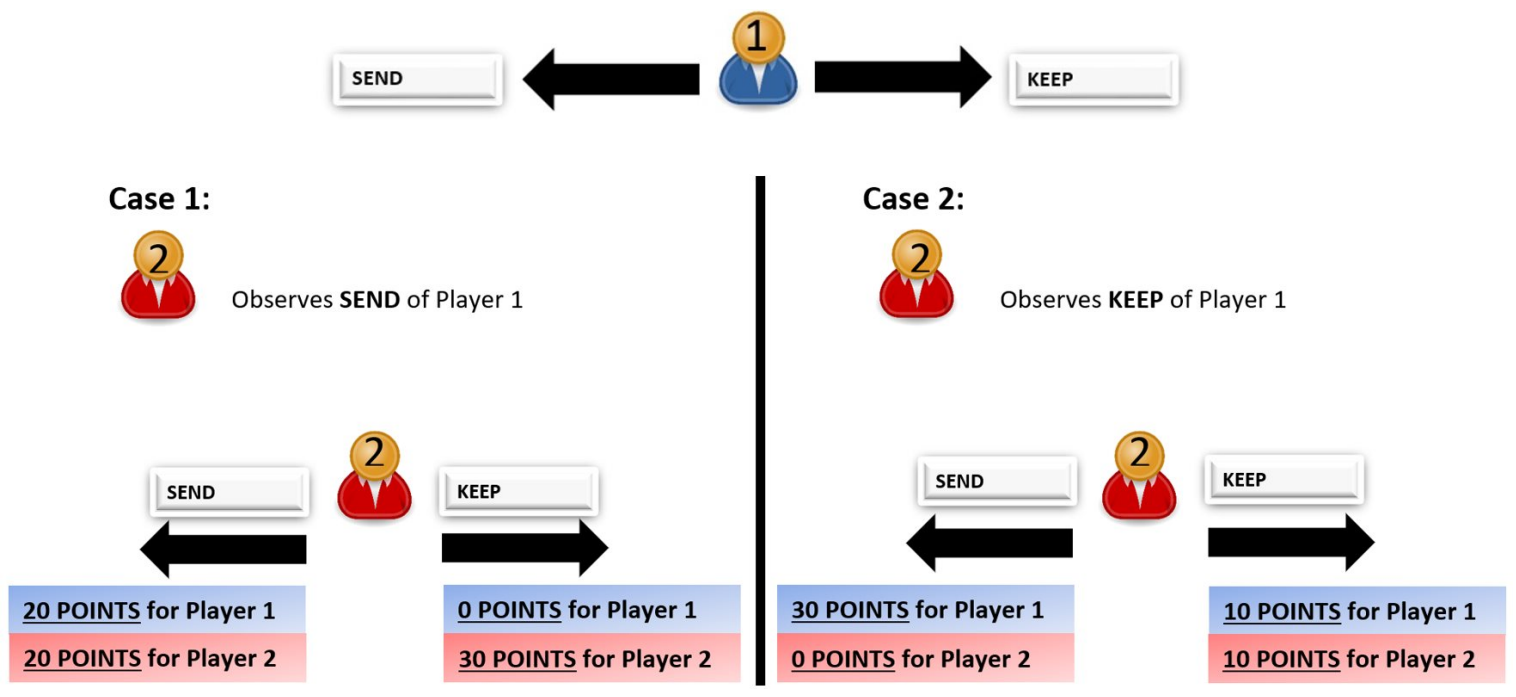

Before starting with the actual decisions, you are asked to answer two short control questions to make sure that you have understood all rules of the game correctly.

\section{Treatment FGF}

You will now be in a group of 4 MTurkers. Each MTurker must decide on the division of 20 POINTS. You can put these 20 POINTS in a private account or you can invest them fully or partially into a project. Any POINT that you do NOT invest into the project, will automatically be transferred to your private account.

Your income from the private account:

For each POINT you put in your private account you will earn exactly one POINT. Nobody except you earns something from your private account.

Your income from the project:

The amount of POINTS contributed to the project by ALL group members, will be increased by $60 \%$ and then equally split among all group members. This means, each group member will receive the same income from the project. Consequently, for each POINT invested in the project each group member (including yourself) receives $1.6 / 4=0.4$ POINTS.

Hence, for each group member the income from the project will be determined as follows:

Income from the project $=$ sum of contributions to the project $\mathrm{x} 0.4$.

For example, if the sum of all contributions to the project is 70 POINTS, then you 
and all group members will get a payoff of $70 \times 0.4=28$ POINTS each from the project. If the sum of contributions is 15 POINTS, then you and all group members will get a payoff of $15 \times 0.4=6$ POINTS each from the project.

Your total income:

Your total income is the sum of your income from the private account and the project:

Income from the private account $(=\mathbf{2 0}-$ contribution to the project $)$

Income from the project $(=0.4 \times$ Sum of contributions of all four players to the project) $=$ TOTAL INCOME.

Conversion rate: 20 POINTS $=1$ DOLLAR.

\section{Your decisions:}

In this part of the study, each participant has to make two types of decisions. In the following we call them "unconditional contribution" and "conditional table":

With the "unconditional contribution" to the project you have to decide how many of your 20 POINTS you want to invest into the project. You do not know how much the other players will invest.

Your second task is to fill a "contribution table". For each possible average contribution of the other group members (rounded to the nearest integer), you must specify how many POINTS you want to contribute to the project. Thus, you can condition your contribution on the contribution of the other group members.

In each group a random mechanism will select one group member. For the randomly selected group member only the contribution table will be the payoffrelevant decision. For the other three group members only the unconditional contribution will be the payoff-relevant decision. When you make your unconditional contribution and when you fill out the contribution table, you do not know whether you will be selected by the random mechanism. Hence, you have to think carefully about both types of decisions because both can be relevant to you. The combination of the decisions of you and the other group members determines your payoff in this game. 